\title{
Well-Defined Silica-Supported Tungsten(IV)-Oxo Complex: Olefin Metathesis Activity, Initiation, and Role of Brønsted Acid Sites
}

\section{Journal Article}

Author(s):

Chan, Ka Wing (D); Mance, Deni; Safonova, Olga V.; Copéret, Christophe (D)

Publication date:

2019

\section{Permanent link:}

https://doi.org/10.3929/ethz-b-000375833

\section{Rights / license:}

In Copyright - Non-Commercial Use Permitted

\section{Originally published in:}

Journal of the American Chemical Society 141(45), https://doi.org/10.1021/jacs.9b09493

\section{Funding acknowledgement:}

157146 - Monitoring active sites of metathesis catalysts: a combined operando spectroscopy and computational approach (SNF) 


\title{
Well-defined Silica-supported Tungsten(IV)-oxo Complex: Olefin Metathesis Activity, Initiation and Role of Brønsted Acid Sites.
}

\author{
Ka Wing Chan ${ }^{\dagger}$, Deni Mance ${ }^{\dagger}$, Olga V. Safonova ${ }^{\S}$, Christophe Copéret ${ }^{*, \dagger}$ \\ ${ }^{\dagger}$ ETH Zürich, Department of Chemistry and Applied Biosciences, Vladimir Prelog Weg 1-5, CH-8093 Zurich, Swit- \\ zerland \\ $\S$ Paul Scherrer Institute, $\mathrm{CH}-5232$ Villigen, Switzerland
}

\begin{abstract}
Despite the importance of the heterogeneous tungsten-oxo based olefin metathesis catalyst $\left(\mathrm{WO}_{3} / \mathrm{SiO}_{2}\right)$ in industry, understanding of its initiation mechanism is still very limited. It has been proposed that reduced W(IV)-oxo surface species act as precatalysts. In order to understand the reactivity and initiation mechanism of surface W(IV)-oxo species, we synthesized a well-defined silica-supported $\mathrm{W}(\mathrm{IV})$-oxo species $(\equiv \mathrm{SiO}) \mathrm{WO}\left(\mathrm{O} t \mathrm{BuF}_{6}\right)(\mathrm{py})_{3}\left(\mathrm{O}_{\mathrm{BuF}}=\right.$ $\mathrm{OC}\left(\mathrm{CH}_{3}\right)\left(\mathrm{CF}_{3}\right)_{2} ;$ py = pyridine $)\left(\mathbf{F 6} @ \mathbf{S i O}_{2-7 o o}\right)$ via Surface Organometallic Chemistry $(\mathrm{SOMC})$. F6@SiO $\mathbf{O}_{2-700}$ was shown to be highly active in olefin metathesis upon removal of pyridine ligands through the addition of

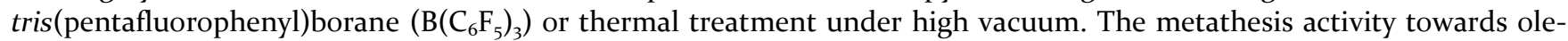
fins with and without allylic $\mathrm{C}-\mathrm{H}$ groups, namely $\beta$-methylstyrene and styrene, respectively, was investigated. In the case of styrene, we demonstrate the role of surface $\mathrm{OH}$ groups in initiating metathesis activity. In particular, the presence of strong Brønsted acidic surface $\mathrm{OH}$ sites, revealed by ${ }^{15} \mathrm{~N}$-labeled pyridine, likely arises from the presence of adjacent $\mathrm{W}$ sites in the catalyst and assist styrene metathesis, an olefin having no allylic $\mathrm{C}-\mathrm{H}$ bond. In contrast, initiation of olefins containing allylic $\mathrm{C}-\mathrm{H}$ group (e.g. $\beta$-methylstyrene) is independent of surface $\mathrm{OH}$ group concentration and likely involves allylic $\mathrm{C}-\mathrm{H}$ activation mechanism like the molecular $\mathrm{W}(\mathrm{IV})$-oxo species. This study indicates that initiation mechanisms depend on the olefinic substrates and reveals the synergistic effect of Brønsted acidic surface sites and reduced W(IV) sites in the initiation of olefin metathesis.
\end{abstract}

\section{INTRODUCTION}

Olefin metathesis is a widely used reaction for applications ranging from petrochemicals to pharmaceuticals. ${ }^{1-13}$ Owing to the high and increasing demand for propene, the tungsten-based heterogeneous catalyst $\left(\mathrm{WO}_{3} / \mathrm{SiO}_{2}\right)$ is used in one of the largest industrial metathesis processes Olefin Conversion Technology (OCT) process, producing propene via ethenolysis of butenes. ${ }^{4}$ Typically, $\mathrm{WO}_{3} / \mathrm{SiO}_{2}$ operates at high temperature $\left(>400{ }^{\circ} \mathrm{C}\right),{ }^{14}$ but various pre-treatment methods, such as thermal treatment under reducing conditions, have been shown to increase the activity at low temperatures. ${ }^{14-22} \mathrm{How}^{-}$ ever, despite years of studies, the molecular-level understanding of the activation process remains very limited and the nature of active species is still under debate. ${ }^{14,21}$ Several studies have reported the formation of oxygenates (e.g. acetone, formaldehyde and acetaldehyde) during the activation of $\mathrm{WO}_{3} / \mathrm{SiO}_{2}$ with propene. ${ }^{20,}{ }^{22-23}$ It has been proposed that the formation of oxygenates is consistent with the formation of reduced W(IV) species that are precursors of the active sites, ${ }^{17}$ ${ }^{19,} 22$ while other studies favor the pseudo-Wittig mechanism that generates the $\mathrm{W}(\mathrm{VI})$ alkylidenes directly (Scheme 1a). ${ }^{18}$

Recently, our group has shown that molecularly-defined silica-supported metal-oxo species and the related $\mathrm{MO}_{3} / \mathrm{SiO}_{2}$ $(\mathrm{M}=\mathrm{Mo}$ or $\mathrm{W})$ can be activated at low temperature $\left(70^{\circ} \mathrm{C}\right)$ by organosilicon reductants. ${ }^{24-25}$ The resulting $\mathrm{M}(\mathrm{IV})$ species initiate metathesis at $70{ }^{\circ} \mathrm{C}$ through in-situ generation of $\mathrm{M}(\mathrm{VI})$ alkylidenes (Scheme $\mathrm{ib}$, an example with W-based system). More recently, we have also shown that molecular $\mathrm{W}(\mathrm{IV})$-oxo complexes, e.g. $\mathrm{WO}(\mathrm{O} t \mathrm{BuF})_{2}(\mathrm{py})_{3}\left(\mathrm{O} t \mathrm{BuF}_{6}=\right.$ $\mathrm{OC}\left(\mathrm{CH}_{3}\right)\left(\mathrm{CF}_{3}\right)_{2}$; py = pyridine), initiate metathesis in the presence of olefins and Lewis acid activators, e.g.

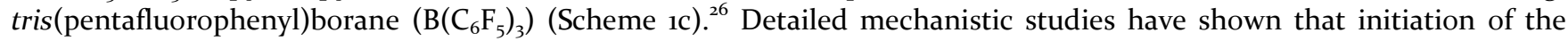
$\mathrm{W}(\mathrm{IV})$ species takes place via allylic $\mathrm{C}-\mathrm{H}$ bond activation of the olefin followed by proton transfers, which is promoted by pyridine to generate the metallacyclobutane. Despite the comparable catalytic performance of these W(IV) systems to well-defined alkylidene complexes, the initiation of W(IV) only leads to the formation of a small amount of active species in solution (few percent of the total W species). The low initiation efficiency can be ascribed to the endergonic nature of this initiation process, as shown by DFT calculations, combined with the fast decomposition of the low-coordinated $\mathrm{W}(\mathrm{IV})$ and $\mathrm{W}(\mathrm{VI})$ intermediates generated in solution. We thus reasoned that generating the corresponding well-defined silica-supported W(IV)-oxo complex could shed light on the initiation mechanism and improve the catalytic performance by preventing some possible deactivation pathways in solution, such as bimolecular decomposition. ${ }^{13,27-32}$ 
Scheme 1. State of the Art in the Initiation of W-based Olefin Metathesis Catalysts. a) $\mathrm{WO}_{3} / \mathrm{SiO}_{2}$. b) $\mathrm{Molecularly}^{-}$ defined Supported W-oxo Species. c) W(IV) Molecular Models.

a) Heterogeneous $\mathrm{WO}_{3} / \mathrm{SiO}_{2}$

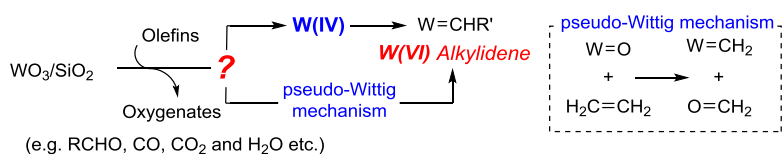

Formation of oxygenates during activation b) Molecularly-defined Supported W-oxo Species

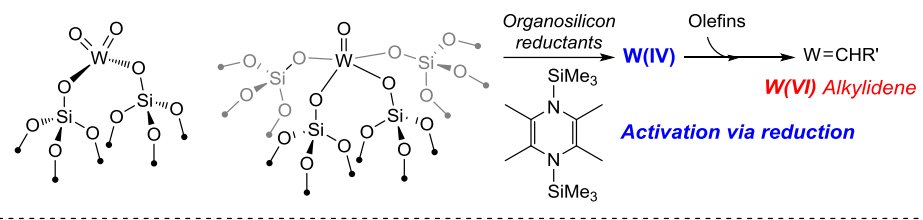

c) W(IV) Molecular Models

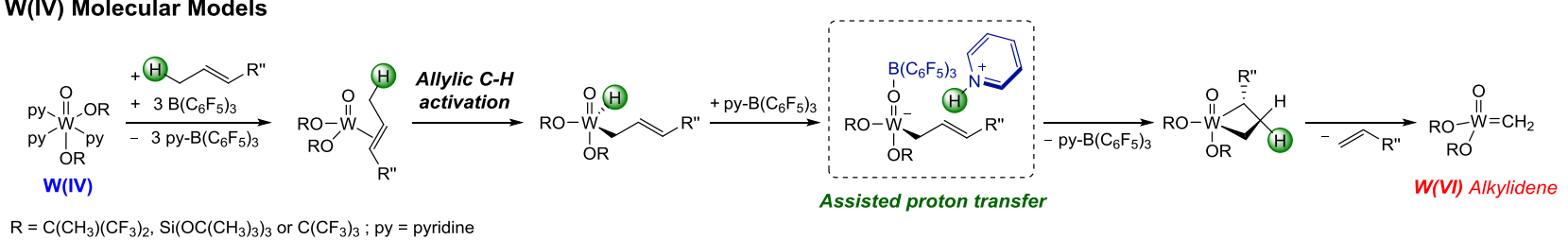

Here, we report the synthesis and the reactivity of well-defined silica-supported W(IV)-oxo species $(\equiv \mathrm{SiO}) \mathrm{WO}\left(\mathrm{O} t \mathrm{BuF}_{6}\right)(\mathrm{py})_{3}\left(\mathrm{O} t \mathrm{BuF}_{6}=\mathrm{OC}\left(\mathrm{CH}_{3}\right)\left(\mathrm{CF}_{3}\right)_{2} ; \mathrm{py}=\right.$ pyridine $)$ prepared via Surface Organometallic Chemistry (SOMC). ${ }^{12,}{ }^{33-35}$ We demonstrate that the supported W(IV) precatalyst is active in olefin metathesis upon activation with $\mathrm{B}\left(\mathrm{C}_{6} \mathrm{~F}_{5}\right)_{3}$ or thermal treatment, which removes the coordinated pyridine ligands. The activated surface species displays one order of magnitude higher catalytic activity than the molecular analogue, and, in contrast to the molecular species, it also catalyzes the self-metathesis of olefins without any allylic $\mathrm{C}-\mathrm{H}$ group, such as styrene. We demonstrate that metathesis activity of styrene is linked to the presence of surface $\mathrm{OH}$ groups that open other initiation pathways involving additional proton-transfer steps in the in-situ formation of alkylidene species.

\section{RESULTS AND DISCUSSION}

Synthesis and characterization of $(\equiv \mathrm{SiO}) \mathrm{WO}\left(\mathrm{OtBuF} \mathrm{F}_{6}\right)(\mathrm{py})_{3}$. Grafting of $\mathrm{WO}\left(\mathrm{O} t \mathrm{BuF}_{6}\right)_{2}(\mathrm{py})_{3}(\mathbf{F 6})$ on silica partially dehydroxylated at $700{ }^{\circ} \mathrm{C}\left(\mathrm{SiO}_{2-700}\right)$ in benzene for $24 \mathrm{~h}$ afforded a dark blue material $\mathbf{F 6} @ \mathbf{S i O}_{2-700}$ (Scheme 2). Analysis of the combined supernatant and washings of the material by ${ }^{1} \mathrm{H}$ NMR spectroscopy revealed the consumption of $\mathbf{F} \mathbf{6}$ and the release of $\mathrm{HO} \mathrm{BuF}_{6}$ ( 0.72 equiv. per grafted $\mathrm{W}$ center) suggesting that grafting occurred via protonolysis. Furthermore, no free pyridine was observed in the washings.

Scheme 2. Preparation of Well-defined Silica-supported W(IV)-Oxo Species

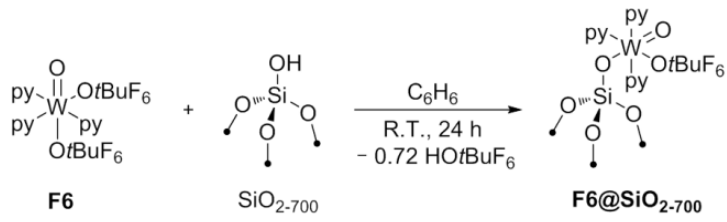

Comparison of the IR spectra of $\mathbf{F 6} @ \mathbf{S i O}_{2-70 o}$ and $\mathrm{SiO}_{2-700}$ reveal the disappearance of isolated silanol $v(\mathrm{O}-\mathrm{H})$ at 3747 $\mathrm{cm}^{-1}$ upon grafting (Figure $\mathrm{S} 1$ ), while a broad red shifted band appears at $3700 \mathrm{~cm}^{-1}$ indicating the interactions between remaining surface silanols and the grafted species. Additional $v(\mathrm{C}-\mathrm{H})$ bands of the alkoxide and pyridine ligands are observed in the region of $3200-2800 \mathrm{~cm}^{-1}$ and $1630-1360 \mathrm{~cm}^{-1}$. The $v_{19 \mathrm{~b}}$ and $v_{8 \mathrm{a}}$ ring-breathing vibrations modes of pyridine ligands also appear in the region of $1630-1440 \mathrm{~cm}^{-1}$, indicating the presence of pyridine on the surface. Elemental analysis of $\mathbf{F 6} @ \mathrm{SiO}_{2-700}$ reveals $3.82 \mathrm{wt} \%$ of W (i.e. o.6 $\mathrm{Wnm}^{-2}$ ) and the composition of $19 \mathrm{C}, 17 \mathrm{H}, 4 \mathrm{~N}$ and $6 \mathrm{~F}$ per W center. These data are consistent with the formation of $(=\mathrm{SiO}) \mathrm{WO}\left(\mathrm{O} t \mathrm{BuF}_{6}\right)(\mathrm{py})_{3}$ as shown in Scheme 1. Further analysis of $\mathbf{F 6} @ \mathbf{S i O}_{2-70 o}$

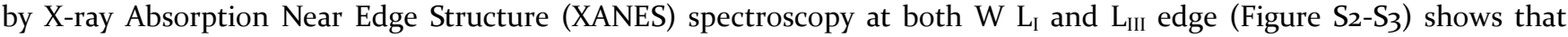
$\mathbf{F 6}_{\mathbf{S}} \mathrm{SiO}_{2-7 \mathbf{0 o}}$ shares the same edge energy and spectroscopic features as $\mathbf{F 6}$, indicating retention of the oxidation state and geometry upon grafting. The lack of pre-edge feature in the $\mathrm{W} \mathrm{L}_{\mathrm{I}}$ edge XANES spectrum further supports that the grafted species remains in an octahedral geometry. Extended X-ray Absorption Fine Structure (EXAFS) fitting analysis of the first coordination sphere of $\mathbf{F 6} @ \mathbf{S i O}_{2-70 o}$ is also consistent with the structure $(\equiv \mathrm{SiO}) \mathrm{WO}(\mathrm{OtBuF})_{6}(\mathrm{py})_{3}$ ( Table 1). ${ }^{1} \mathrm{H}$ Magic Angle Spinning (MAS) NMR spectrum of $\mathbf{F 6} @ \mathbf{S i O}_{2-700}$ displays two signals at $\delta 1.95$ and $1.69 \mathrm{ppm}$ (Figure S6) indicating the presence of $-\mathrm{CH}_{3}\left(\mathrm{CF}_{3}\right)_{2}$ groups in two different environments. Additional proton resonances at $\delta 8.88$ and $7.71 \mathrm{ppm}$ indicate the presence of pyridine ligands. Similarly, ${ }^{19} \mathrm{~F}$ MAS NMR spectrum shows a broad signal at ca. $\delta-81 \mathrm{ppm}$ corresponding to the $-\mathrm{CF}_{3}$ groups (Figure $\mathrm{S}_{7}$ ). These chemical shifts are similar to the reported $\mathbf{F} \mathbf{6}$ molecular analogue. ${ }^{26}$ 
Table 1. EXAFS Fit Parameters for the W $\mathrm{L}_{\mathrm{III}}$-edge Spectrum of F6@SiO

\begin{tabular}{l|lll} 
neighbor & $\mathrm{N}^{a}$ & $\sigma^{2}\left(\AA^{2}\right)^{b}$ & $\mathrm{R}(\AA)^{c}$ \\
\hline $\mathrm{O}$ & $1^{*}$ & $0.002(2)$ & $1.73(1)$ \\
$\mathrm{O}$ & $2^{*}$ & $0.003(2)$ & $2.00(3)$ \\
$\mathrm{N}$ & $3^{*}$ & $0.005(3)$ & $2.16(4)$
\end{tabular}

${ }^{a}$ Number of specified neighbors. ${ }^{b}$ Debye-Waller factor. ${ }^{c}$ Distance between $\mathrm{W}$ metal center to the specified neighbors. ${ }^{*}$ Fixed parameters in the fit.

Catalytic activity. We then examined the catalytic activity of $\mathbf{F 6} @ \mathbf{S i O}_{2-7 \mathbf{o o}}$ towards self-metathesis of cis-4-nonene at 70 ${ }^{\circ} \mathrm{C}$. In the absence of activation, this material displays no metathesis activity, similar to what was observed with the F6 molecular compound. ${ }^{26}$ However, upon the addition of $\mathrm{B}\left(\mathrm{C}_{6} \mathrm{~F}_{5}\right)_{3}$ (3 equiv per $\mathrm{W}$ ) to remove the coordinated pyridine ligands, $\mathbf{F 6}_{\mathrm{S}} \mathrm{SiO}_{2-7 \text { oo }}$ catalyzes self-metathesis of cis-4-nonene (10oo equiv per $\mathrm{W}$ ) at $70{ }^{\circ} \mathrm{C}$ reaching equilibrium conversion $(51 \%)$ within $3 \mathrm{~h}$ (Figure $\mathrm{S} 13)$. To quantify the amount of pyridine that was abstracted by $\mathrm{B}\left(\mathrm{C}_{6} \mathrm{~F}_{5}\right)_{3}, \mathbf{F}_{6} @ S i \mathrm{O}_{2-70 o}$ was contacted with $\mathrm{B}\left(\mathrm{C}_{6} \mathrm{~F}_{5}\right)_{3}$ (3 equiv per $\mathrm{W}$ ) in the absence of olefin, and the amount of py-B $\left(\mathrm{C}_{6} \mathrm{~F}_{5}\right)_{3}$ quantified suggests that at least 2.2 equiv of pyridine (per W) was removed. Alternatively, thermal treatment of $\mathbf{F}_{6} @ S \mathrm{SiO}_{2-700}$ at $400{ }^{\circ} \mathrm{C}$ under high vacuum also removes the coordinated pyridines, resulting in a metathesis active material $\mathbf{F 6}_{\mathbf{6}} @ \mathbf{S i O}_{\mathbf{2 - 7}}$ oo-thermal, without the need of any activator. Under the same reaction conditions with cis-4-nonene, while a short induction period of ca. 30 min is observed in the case of $\mathbf{F 6} @ \mathbf{S i O}_{\mathbf{2 - 7 0 o}-\text { thermal }}$, equilibrium conversion is reached within 2 h (Figure S13). The high temperature thermal treatment used would also lead to additional surface reactions including the formation of surface sites with

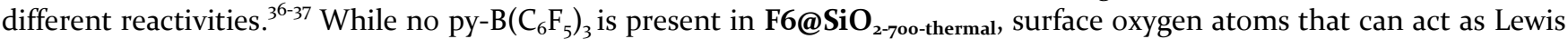
base might play a similar role in proton transfers. ${ }^{3-40}$ It is noteworthy that $\mathbf{F 6} @ \mathbf{S i O}_{\mathbf{2 - 7 0 o}}$ displays a significantly higher catalytic activity compared to its $\mathbf{F 6}$ homogeneous analogue (Table 2). This difference in activity points to the advantage of site isolation in the supported $\mathbf{F 6 @ S i O} \mathbf{S}_{\mathbf{2 - 7 0 o}}$, which likely prevents bimolecular deactivation of low-coordinated reaction intermediates, thus improves catalyst stability. ${ }^{41}$

Table 2. Catalytic Activities of Supported and Molecular Species in Olefin Metathesis ${ }^{a}$

\begin{tabular}{|c|c|c|c|c|}
\hline catalysts & $\begin{array}{l}\mathrm{mol} \\
\%^{\mathrm{c}}\end{array}$ & substrate & $\begin{array}{l}\text { rate } \\
\left(\min ^{-1}\right)^{f}\end{array}$ & $\begin{array}{l}\text { conv. } \\
\text { at } 6 h^{g}\end{array}$ \\
\hline F6@SiO & 0.1 & Cis-4-nonene & $14^{d}$ & $\begin{array}{l}\text { Equil.; } \\
3 \mathrm{~h}\end{array}$ \\
\hline $\begin{array}{l}\mathrm{F6} @ \mathrm{SiO}_{b}-\mathrm{zoo-} \\
\text { thermal }\end{array}$ & 0.1 & Cis-4-nonene & $28^{d, h}$ & $\begin{array}{l}\text { Equil.; } \\
2 \mathrm{~h}\end{array}$ \\
\hline F6 & 0.3 & Cis-4-nonene & $2^{d}$ & $47 \%$ \\
\hline $\mathrm{F} @ \mathrm{SiO}_{2-7 o o}$ & 1 & 1-nonene & $2^{d}$ & $86 \%$ \\
\hline $\mathrm{F} @ \mathrm{SiO}_{2-700}$ & 2 & $\begin{array}{l}\beta \text { - } \\
\text { methylstyrene }\end{array}$ & $0.4^{e}$ & $59 \%$ \\
\hline $\mathrm{F} @ \mathrm{SiO}_{2-7 \mathrm{oo}}$ & 2 & Styrene & $0.1^{e}$ & $40 \%$ \\
\hline F6 & 2 & $\begin{array}{l}\beta- \\
\text { methylstyrene }\end{array}$ & $<0.01^{e, h}$ & $12 \%$ \\
\hline
\end{tabular}

${ }^{a}$ Batch reactor, $70{ }^{\circ} \mathrm{C}$, in the presence of $\mathrm{B}\left(\mathrm{C}_{6} \mathrm{~F}_{5}\right)_{3}$ (3 equiv per $\left.\mathrm{W}\right) .{ }^{b}$ Without $\mathrm{B}\left(\mathrm{C}_{6} \mathrm{~F}_{5}\right)_{3} .{ }^{c}$ Catalyst loadings based on $\mathrm{W}$ mol $\%$. ${ }^{d} 1.0$ M toluene solution. ${ }^{e}$ o.2 M toluene solution. ${ }^{f}$ Rate of metathesis (mol of product $/ \mathrm{mol}$ of W/min) at conversion $<20 \%$. ${ }^{g} \mathrm{Conver-}$ sion at $6 \mathrm{~h}$ unless otherwise noted by giving the time reaching equilibrium conversion. ${ }^{h}$ Following an induction period (ca. 30 $\min )$, the metathesis starts and reaches a maximum rate after $60 \mathrm{~min}$.

We then investigated the metathesis activity towards other olefins including 1-nonene, trans- $\beta$-methylstyrene and styrene. The results are summarized in Table 2 . In the presence of $B\left(C_{6} F_{5}\right)_{3}$, self-metathesis of 1-nonene catalyzed by $\mathbf{F 6}_{\mathrm{SiO}}$-70o reaches $86 \%$ conversion at $6 \mathrm{~h}$ (Figure S14). The rate of self-metathesis of trans- $\beta$-methylstyrene catalyzed by

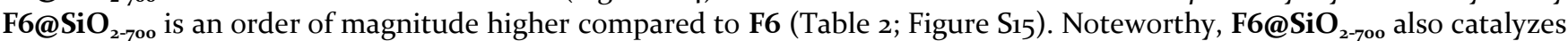
the self-metathesis of styrene while F6 does not, under similar reaction conditions (Figure S16). These results indicate that immobilization of the precatalyst on silica enables efficient metathesis for substrate without allylic $\mathrm{C}-\mathrm{H}$ group, indicating the contribution of alternative initiation mechanism and possibly the involvement of surface OH groups, which are not present in the molecular system (vide infra). ${ }^{14,42-43}$

Effects of surface $\mathrm{OH}$ densities. In order to investigate the possible involvement of surface OH groups in facilitating initiation, the molecular complex F6 was grafted on silica with varying initial surface $\mathrm{OH}$ densities, that can be achieved through controlling the dehydroxylation temperatures of the supports $\left(\mathrm{SiO}_{2-\mathrm{x}}, \mathrm{x}=\right.$ dehydroxylation temperatures in $\left.{ }^{\circ} \mathrm{C}\right)$, namely $\mathrm{SiO}_{2-500}\left(0.46 \mathrm{mmol}_{\mathrm{OH}} / \mathrm{g} ; 1.4 \mathrm{OH} / \mathrm{nm}^{2}\right)$ and $\mathrm{SiO}_{2-200}\left(0.84 \mathrm{mmol}_{\mathrm{OH}} / \mathrm{g} ; 2.5 \mathrm{OH} / \mathrm{nm}^{2}\right)$ yielding $\mathbf{F 6 @ S i O}{ }_{2-500}$ and

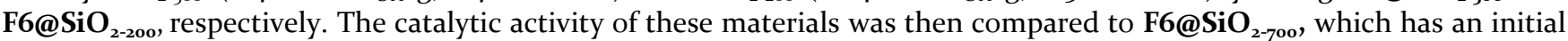
$\mathrm{OH}$ density of $0.31 \mathrm{mmol}_{\mathrm{OH}} / \mathrm{g}\left(0.9 \mathrm{OH} / \mathrm{nm}^{2}\right)$ on $\mathrm{SiO}_{2-700}$. In all materials, the weight loadings of W were kept the same, i.e. 
with a density of ca. $0.6 \mathrm{Wnm}^{-2}$, yielding materials with different densities of remaining silanols. However, a small amount of bis-grafted W sites (up to ca. $27 \%$ of total surface W) could be present in $\mathbf{F 6} @ \mathbf{S i O} \mathbf{2}_{2-20 o}$, based on mass balance analysis (see ESI for details). IR spectra of the grafted materials (Figure 1) indicate that no isolated silanol $\left(3747 \mathrm{~cm}^{-1}\right)$ remains, while broad $\mathrm{OH}$ bands - associated with $\mathrm{OH}$ groups interacting with the grafted species - appear at $3690-3700 \mathrm{~cm}^{-1}$. The intensities of $\mathrm{OH}$ bands increase with the initial $\mathrm{OH}$ density: $\mathbf{F 6} @ \mathbf{S i O}_{2-200}>\mathbf{F 6} @ \mathbf{S i O}_{2-500}>\mathbf{F 6} @ \mathbf{S i O} \mathbf{O}_{\text {2-70o }}$.

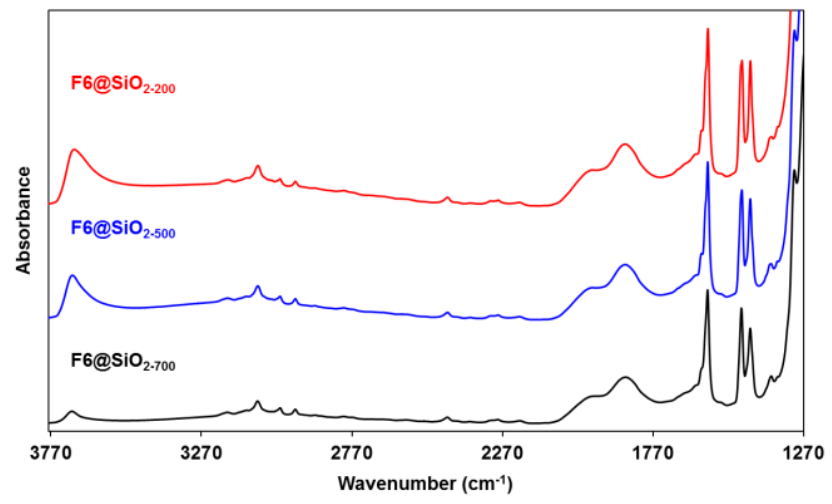

Figure 1. IR spectra of $\mathbf{F 6 @ S i O}{ }_{2-20 o}$ (red; top), $\mathbf{F 6 @ S i O}{ }_{2-50 o}$ (blue; middle) and $\mathbf{F 6 @ S i O}$ 2-7oo (black; bottom).

The catalytic activities of $\mathbf{F 6 @ S i O} \mathbf{2 - 7 0 o}_{2}, \mathbf{F 6} @ \mathbf{S i O}_{2-500}$ and $\mathbf{F 6 @ S i O} \mathbf{S}_{\text {2-2oo }}$ in the self-metathesis of trans- $\beta$-methylstyrene and styrene in the presence of $\mathrm{B}\left(\mathrm{C}_{6} \mathrm{~F}_{5}\right)_{3}$ were then investigated. The rates of self-metathesis of trans- $\beta$-methylstyrene are similar for all three materials, while the rates of styrene self-metathesis parallel the increasing $\mathrm{OH}$ densities of the materials (Figure 2). The rate of styrene metathesis catalyzed by $\mathbf{F 6 @ S i O} \mathbf{~}_{2-20 o}$ is approximately 2.5 times higher compared to $\mathbf{F 6} @ \mathbf{S i O}_{\text {2-70o. }}$. The increases in activities with increasing $\mathrm{OH}$ densities and the lack of styrene metathesis activity in F6 molecular system further point to the involvement of surface $\mathrm{OH}$ groups in the initiation step with styrene, an olefin without an allylic $\mathrm{C}-\mathrm{H}$ bond (vide infra).

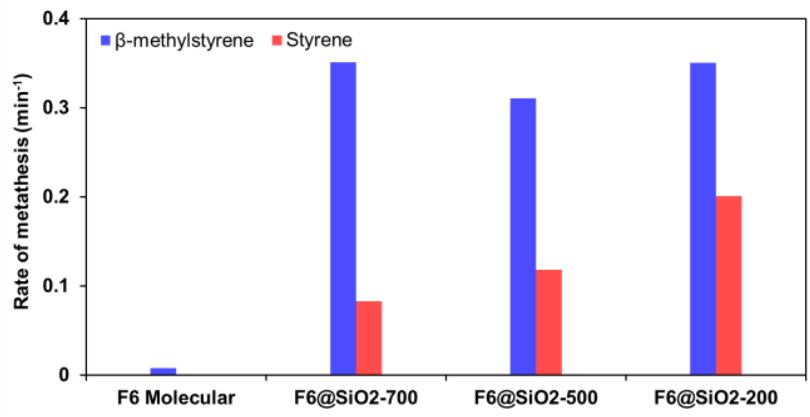

Figure 2. Rates of metathesis $\left(\mathrm{min}^{-1}\right)$ (at conversion $\left.<20 \%\right)$ of $\mathbf{F 6}, \mathbf{F 6} @ S \mathbf{O}_{2-700}, \mathbf{F 6} @ S i O_{2-500}$ and $\mathbf{F 6} @ S i O_{2-20 o}$ for trans- $\beta$ methylstyrene (blue) and styrene (red).

Investigations of reaction intermediates formed upon reaction of $\mathbf{F 6} @ \mathbf{S i O}_{2-2 o o}$ with styrene. To investigate the reaction intermediates formed on the surface, $\mathbf{F 6} @ \mathbf{S i O}_{2-2 o o}$ was exposed to ${ }^{13} \mathrm{C}$-dilabeled styrene- $\alpha, \beta{ }^{13} \mathrm{C}_{2}$ in the presence of $\mathrm{B}\left(\mathrm{C}_{6} \mathrm{~F}_{5}\right)_{3}$ in toluene at $70^{\circ} \mathrm{C}$ for $1 \mathrm{~h}$. The supernatant was then removed, and the solid was washed with toluene, followed by drying under high vacuum. ${ }^{13} \mathrm{C}$ solid-state NMR spectrum of the resulting solid reveals a major signal at ca. $\delta 65 \mathrm{ppm}$ (Figure S18), which indicates the presence of ethylene $\pi$ complex formed from the ethylene released during styrene metathesis. This assignment is further confirmed by the ${ }^{13} \mathrm{C}-{ }^{13} \mathrm{C}$ single-quantum double-quantum SQ-DQ experiment (Figure 3 ), in which a strong self-correlating signal at $\delta 130 \mathrm{ppm}$ in the DQ dimension and $\delta 65 \mathrm{ppm}$ in the SQ dimension was observed. Noticeably, this self-correlating signal appears to be very broad, indicating a distribution of surface W ethylene $\pi$ complexes likely associated with slightly different environments. In addition, two intense signals at $\delta 65$ and $85 \mathrm{ppm}$ that correlate with each other (Figure 3) are assigned to the $\beta$ - and $\alpha$-carbons of the styrene $\pi$ complex, respectively. The signals at $\delta 75$ $\operatorname{ppm}(\alpha-\mathrm{C})$ and $36 \mathrm{ppm}(\beta-\mathrm{C})$ are also correlated in the SQ-DQ experiment and are attributed to the $\alpha$ - and $\beta$ - carbons of the unsubstituted metallacyclopentane. The observation of both olefin $\pi$ complexes and metallacyclopentane as the major species is in line with what was observed in the $\mathbf{F 6}$ molecular system. ${ }^{26}$ However, the absence of evidence for alkylidenes or metallacyclobutanes is noteworthy; it implies that the number of active species formed is likely small, possibly pointing out the low efficiency of the initiation process due to the competing and favorable formation of olefin $\pi$ complexes and metallacyclopentane. ${ }^{26}$ Finally, two additional signals at $\delta 61$ and $19 \mathrm{ppm}$ are assigned to the presence of ethoxy group 
(EtO-) on the surface, ${ }^{44-45}$ which arise from the protonation of ethylene by surface OH groups. Such species are not observed on silica (see ESI for details) suggesting the presence of highly Brønsted acidic OH groups in $\mathbf{F 6 @ S i O} \mathbf{2 - 2 o o}_{\text {under }}$ reaction conditions.

We also attempted to quantify the amount of active alkylidenes formed by cross-metathesis reactions between styrene and cis-5-decene. However, the presence of off cycle species (e.g. olefin $\pi$ complex and metallacyclopentane) that can serve as an olefin reservoir for subsequent cross-metathesis reactions have prevented us from obtaining a reliable quantification of the active alkylidene species.

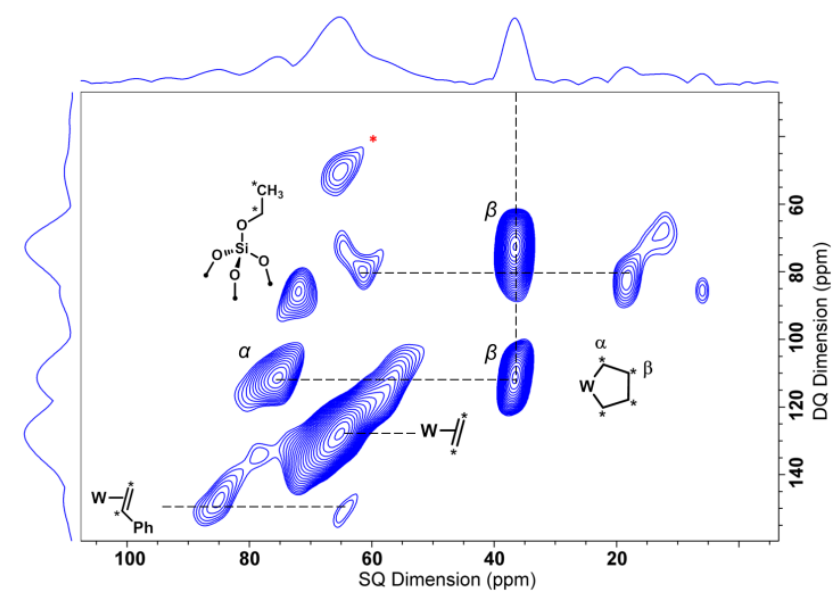

Figure $3 .{ }^{13} \mathrm{C}-{ }^{13} \mathrm{C}$ SQ-DQ MAS NMR experiment acquired on a $600 \mathrm{MHz}$ spectrometer at $12 \mathrm{kHz}$ MAS of $\mathbf{F 6} @ \mathbf{S i O}_{2-20 o}$ after contacting with styrene- $\alpha, \beta-{ }^{13} C_{2}$ under reaction conditions. Asterisk (in red) indicates spinning sideband.

Brønsted acidic sites in $\mathbf{F 6} @ S i_{2-2 o o}$ probed by ${ }^{15} \mathrm{~N}$-pyridine. The observation of surface EtO- group (Figure 3) upon contacting $\mathbf{F 6} @ \mathrm{SiO}_{2-200}$ with styrene- $\alpha, \beta-{ }^{13} \mathrm{C}_{2}$ under reaction conditions suggests the presence of strong Brønsted acidic sites, which are further evidenced by using ${ }^{15} \mathrm{~N}$-labeled pyridine $\left({ }^{15} \mathrm{~N}\right.$-py) as a probe molecule. ${ }^{15} \mathrm{~N}$-labeled $\mathbf{F} 6 @ S \mathbf{O}_{2-200}\left({ }^{15} \mathrm{~N}\right.$ F6@SiO ${ }_{2-200}$ ) was synthesized and its ${ }^{15} \mathrm{~N}$ Cross-polarization (CP) MAS NMR spectrum shows similar ${ }^{15} \mathrm{~N}$ resonance signals compared to the ${ }^{15} \mathrm{~N}$-labeled molecular precursor $\left({ }^{15} \mathrm{~N}-\mathrm{F} 6\right)$ (Figure S19) along with a small peak at $\delta 293 \mathrm{ppm}$ indicating a small amount of ${ }^{15} \mathrm{~N}$-py that is $\mathrm{H}$-bonded to the $\mathrm{OH}$ groups on the surface, likely released upon grafting. ${ }^{46-47}$ Upon activation of the ${ }^{15} \mathrm{~N}-\mathrm{F} 6 @ \mathrm{SiO}_{2-200}$ with 3 equiv of $\mathrm{B}\left(\mathrm{C}_{6} \mathrm{~F}_{5}\right)_{3}$ at $7 \mathrm{o}^{\circ} \mathrm{C}$, followed by the subsequent addition of extra ${ }^{15} \mathrm{~N}-\mathrm{py}$, a shift in the major ${ }^{15} \mathrm{~N}$ signals to lower chemical shifts, compared to ${ }^{15} \mathbf{N}-\mathbf{F 6} @ \mathbf{S i O}_{2-20 o}$, was observed. This result indicates that some of the changes in the coordination environment of the $\mathrm{W}$ centers after the removal of ${ }^{15} \mathrm{~N}$-py ligands by $\mathrm{B}\left(\mathrm{C}_{6} \mathrm{~F}_{5}\right)_{3}$ are irreversible and that the surface remaining ${ }^{15} \mathrm{~N}-\mathrm{py}-\mathrm{B}\left(\mathrm{C}_{6} \mathrm{~F}_{5}\right)_{3}$ adducts formed likely contribute to the signal observed. ${ }^{48}$ Notably, a small peak at $\delta 207 \mathrm{ppm}$ also appeared, which is attributed to pyridinium $\left({ }^{15} \mathrm{~N}-\mathrm{pyH}^{+}\right)$(Figure $\left.\mathrm{S}_{19}\right){ }^{46-47}$ The presence of ${ }^{15} \mathrm{~N}-\mathrm{pyH}^{+}$is further supported by the peak observed at $1533 \mathrm{~cm}^{-1}$ in the IR spectrum corresponding to a combination of vibration modes involving ${ }^{15} \mathrm{~N}^{+}-\mathrm{H}$ (Figure S2o). ${ }^{49-51}$ The formation of ${ }^{15} \mathrm{~N}-\mathrm{pyH}^{+}$by protonating the ${ }^{15} \mathrm{~N}$-py indicates the presence of strong Brønsted acidic site upon addition of $\mathrm{B}\left(\mathrm{C}_{6} \mathrm{~F}_{5}\right)_{3}$ to ${ }^{15} \mathbf{N}-\mathbf{F 6} @ \mathbf{S i O}_{2-20 o}$. Notably, such Brønsted acidic sites are absent on $\mathrm{SiO}_{2-200}$, despite the presence of pyridine and $\mathrm{B}_{(}\left(\mathrm{C}_{6} \mathrm{~F}_{5}\right)_{3}$ (Figure $\mathrm{S2O}$ ), indicating the low-coordinated $\mathrm{W}$ center is likely responsible for the formation of the strong Brønsted acid site by interacting with the $\mathrm{OH}$ group in close proximity.

Proposed initiation mechanism for the formation of alkylidenes. Based on the above observations: i) the increase activity in styrene metathesis parallels the increase in surface $\mathrm{OH}$ density (Figure 1), and ii) the presence of strong Brønsted acidic sites in the supported system due to the presence of low-coordinated $\mathrm{W}$ centers as shown by the ${ }^{15} \mathrm{~N}$-py experiments, we propose that for olefins having no allylic $\mathrm{C}-\mathrm{H}$ group, e.g. styrene, surface $\mathrm{OH}$ groups can assist the initiation by protonating the olefins or the $\mathrm{W}$ center as shown in Scheme $3 .{ }^{14,}{ }^{42-43}$ Protonation of the W-coordinated olefin by surface $\mathrm{OH}$ groups can directly lead to the formation of tungsten-carbon bond, a tungsten alkyl species. Alternatively, protonation of the free olefin can yield transient carbocations that can either generate surface alkoxy groups that are observed experimentally (Figure 3) or further react with the W(IV) centers forming the tungsten alkyl species. Another possibility would be protonating the $\mathrm{W}$ center to generate $\mathrm{W}-\mathrm{H}$ species that can undergo insertion with an olefin to yield tungsten alkyl species. Subsequent deprotonation of the tungsten alkyl species by the silanolate ligand leads to the formation of an alkylidene. 


\section{Scheme 3. Proposed Initiation Mechanisms for Olefin Without Allylic C-H Group.}

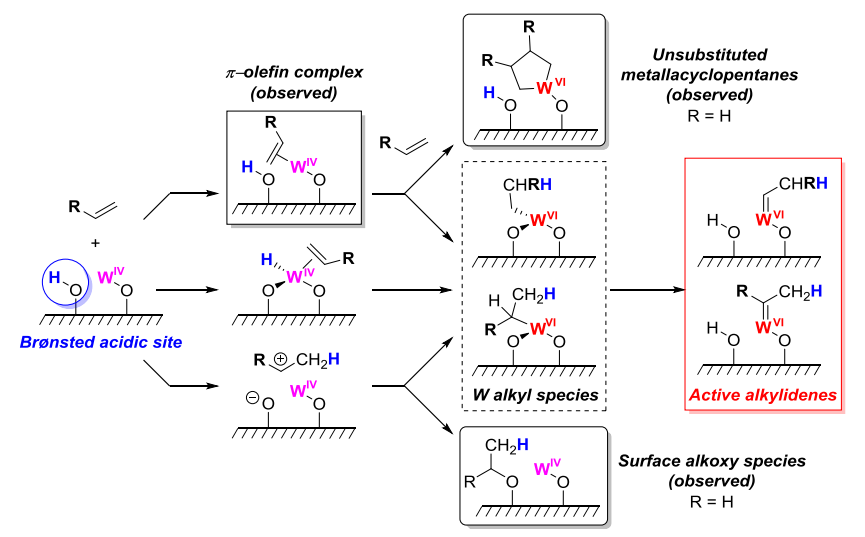

The proposed carbocation intermediates could also lead to an indirect initiation pathway involving dimerization of styrene followed by the allylic $\mathrm{C}-\mathrm{H}$ activation. ${ }^{52-53}$ However, the corresponding dimer does not initiate metathesis as shown in the molecular $\mathbf{F 6}$ system (see ESI for details), precluding the possibility of the latter initiation pathway. The feasibility of the proposed initiation mechanism in Scheme 3 is also supported by DFT calculations, which suggest the initiation pathway, especially the formation of tungsten alkyl from W(IV) species is thermodynamically favorable. The calculations also show that subsequent deprotonation of the alkyl ligand would be thermoneutral in specific environments, i.e. with a slightly elongated $\mathrm{W}-\mathrm{O}$ silanolate bond, which is only possible for a small amount of surface strained sites (see ESI for details). This likely contributes to the formation of only a small amount of active sites associated with low initiation efficiency. In order to obtain more insight into the initiation mechanism, we also tried to track the initiation product formed in the process. However, unlike the reported homogeneous F6 system, ${ }^{26}$ monitoring the metathesis of either $\beta$ methylstyrene or styrene by GC-MS does not reveal the formation of a specific initiation product, which may be due to strong adsorption on the surface and further reactions. Although there is no direct initiation product observed in F6@SiO ${ }_{2-\mathrm{x}}$ during the generation of alkylidene species, we propose that olefins with allylic $\mathrm{C}-\mathrm{H}$ groups likely follow the allylic $\mathrm{C}-\mathrm{H}$ activation mechanism and subsequent proton transfers to generate the metallacyclobutane intermediates, as reported in the molecular $\mathbf{F 6}$ system. ${ }^{26}$ Since increasing $\mathrm{OH}$ density does not lead to an increase in the metathesis activity with the trans- $\beta$-methylstyrene (Figure 1), this suggests the presence of competing initiation mechanisms, e.g. allylic $\mathrm{C}-\mathrm{H}$ bond activation that depend on the olefinic substrates.

\section{CONCLUSION}

We have shown that well-defined $\mathrm{W}(\mathrm{IV})$ oxo species $(\equiv \mathrm{SiO}) \mathrm{WO}\left(\mathrm{O} t \mathrm{BuF}_{6}\right)(\mathrm{py})_{3}\left(\mathbf{F} 6 @ \mathbf{S i O}_{\text {2-7oo }}\right)$ prepared via SOMC is ac-

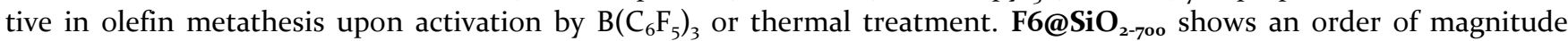
higher catalytic activity compared to the $\mathbf{F 6}$ molecular analogue, confirming the advantage of site isolation when reactive intermediates are formed. Furthermore, $\mathbf{F 6} @ \mathbf{S i O}_{2-70 o}$ also initiates the self-metathesis of styrene in sharp contrast to the reported F6 suggesting that alternative initiation mechanisms are involved in supported species. The fact that increasing surface $\mathrm{OH}$ densities of the supports further increases the rates of styrene metathesis suggests a surface proton assisted initiation mechanism for olefins without allylic $\mathrm{C}-\mathrm{H}$ group. This is also consistent with the generation of strong Brønsted acidic surface sites in the activated catalysts. For substrates with allylic $\mathrm{C}-\mathrm{H}$ groups e.g. $\beta$-methylstyrene, initiation via allylic $\mathrm{C}-\mathrm{H}$ activation is still likely involved, as evidenced by the lack of dependence of metathesis activity with $\mathrm{OH}$ density. This study suggests that initiation mechanisms for generating W-based olefin metathesis catalysts from W(IV)-oxo species depend on the olefinic substrates. Furthermore, these findings reveal the participation of the surface functionalities of oxide support, namely the surface Brønsted acid sites. It is noteworthy that initiation of metathesis catalysts (whether involving allylic $\mathrm{C}-\mathrm{H}$ activation or not) involves a key proton transfer step. This also indicates that oxide supports in heterogeneous olefin metathesis catalysts might not always be inert, even for a support like silica. Surface Brønsted acidic sites formed in the presence of $\mathrm{W}$ can be responsible for metathesis activity by opening alternative initia- 
tion processes. This study helps to further understand the effects of Brønsted acidity in heterogeneous metathesis catalysts.

\section{ASSOCIATED CONTENT}

Supporting Information. The Supporting Information is available free of charge on the ACS Publications website. Full experimental and computational details and catalytic data. (PDF)

\section{AUTHOR INFORMATION}

\section{Corresponding Author}

* ccoperet@ethz.ch

\section{ACKNOWLEDGMENT}

The authors are grateful to the Swiss National Foundation (SNF) for financial support of this work (grant no. 200o21L_157146). DM acknowledges support from the ETHZ Postdoctoral Fellowship Program and from the Marie Curie Actions for People COFUND Program.

\section{REFERENCES}

1. Grubbs, R. H.; Chang, S., Recent advances in olefin metathesis and its application in organic synthesis. Tetrahedron 1998, 54, 44134450.

2. $\quad$ Fürstner, A., Olefin Metathesis and Beyond. Angew. Chem. Int. Ed. 20oo, 39, 3012-3043.

3. Schrock, R. R.; Hoveyda, A. H., Molybdenum and Tungsten Imido Alkylidene Complexes as Efficient Olefin-Metathesis Catalysts. Angew. Chem. Int. Ed. 2003, 42, 4592-4633.

4. Mol, J. C., Industrial applications of olefin metathesis. J. Mol. Catal. A: Chem. 2004, 213, 39-45.

5. Schrock, R. R., Multiple Metal-Carbon Bonds for Catalytic Metathesis Reactions (Nobel Lecture). Angew. Chem. Int. Ed. 20o6, 45, 3748-3759.

6. Hoveyda, A. H.; Zhugralin, A. R., The remarkable metal-catalysed olefin metathesis reaction. Nature 2007, 450, 243.

7. Hoveyda, A. H.; Malcolmson, S. J.; Meek, S. J.; Zhugralin, A. R., Catalytic Enantioselective Olefin Metathesis in Natural Product Synthesis. Chiral Metal-Based Complexes that Deliver High Enantioselectivity and More. Angew. Chem. Int. Ed. 20o9, 49 , 34-44.

8. Grubbs, R. H.; Wenzel, A. G.; O’Leary, D. J.; Khosravi, E., Handbook of Metathesis, 3 Vol. Set, 2nd ed. Wiley VCH: Weinheim: 2015.

9. Higman, C. S.; Lummiss, J. A. M.; Fogg, D. E., Olefin Metathesis at the Dawn of Implementation in Pharmaceutical and SpecialtyChemicals Manufacturing. Angew. Chem. Int. Ed. 2016, 55, 3552-3565.

10. Nguyen, T. T.; Koh, M. J.; Shen, X.; Romiti, F.; Schrock, R. R.; Hoveyda, A. H., Kinetically controlled E-selective catalytic olefin metathesis. Science 2016, 352, 569 .

11. Koh, M. J.; Nguyen, T. T.; Lam, J. K.; Torker, S.; Hyvl, J.; Schrock, R. R.; Hoveyda, A. H., Molybdenum chloride catalysts for Z-selective olefin metathesis reactions. Nature 2017, 542, 80.

12. Coperet, C.; Allouche, F.; Chan, K. W.; Conley, M. P.; Delley, M. F.; Fedorov, A.; Moroz, I. B.; Mougel, V.; Pucino, M.; Searles, K.; Yamamoto, K.; Zhizhko, P. A., Bridging the Gap between Industrial and Well-Defined Supported Catalysts. Angew. Chem. Int. Ed. 2018, 57, 63986440.

13. Schrock, R. R., Recent Advances in High Oxidation State Mo and W Imido Alkylidene Chemistry. Chem. Rev. 2009, 109, 3211-3226.

14. Lwin, S.; Wachs, I. E., Olefin Metathesis by Supported Metal Oxide Catalysts. ACS Catal. 2014, 4, 2505-2520.

15. Westhoff, R.; Moulijn, J. A., Reduction and activity of the metathesis catalyst WO3/SiO2. J. Catal. 1977, 46, 414-416.

16. Andreini, A.; Mol, J. C., Activity of supported tungsten oxide catalysts for the metathesis of propene. J. Colloid Interface Sci. 1981, 84,

$57-65$.

17. Basrur, A. G.; Patwardhan, S. R.; Was, S. N., Propene metathesis over silica-supported tungsten oxide catalyst-Catalyst induction mechanism. J. Catal. 1991, 127, 86-95.

18. Ding, K.; Gulec, A.; Johnson, A. M.; Drake, T. L.; Wu, W.; Lin, Y.; Weitz, E.; Marks, L. D.; Stair, P. C., Highly Efficient Activation, Regeneration, and Active Site Identification of Oxide-Based Olefin Metathesis Catalysts. ACS Catal. 2o16, 6, $5740-5746$.

19. Howell, J. G.; Li, Y.-P.; Bell, A. T., Propene Metathesis over Supported Tungsten Oxide Catalysts: A Study of Active Site Formation. ACS Catal. 2016, 6, 7728-7738.

20. Lwin, S.; Wachs, I. E., Catalyst Activation and Kinetics for Propylene Metathesis by Supported $\mathrm{WO}_{\mathrm{x}} / \mathrm{SiO}_{2}$ Catalysts. ACS Catal. 2o17, 7 , $573-580$.

21. Schrock, R. R.; Copéret, C., Formation of High-Oxidation-State Metal-Carbon Double Bonds. Organometallics 2017, 36, 1884-1892. 22. Luckner, R. C.; Wills, G. B., Transient kinetics of the disproportionation of propylene over a tungsten oxide on silica catalyst. J. Catal. 1973, 28, 83-91.

23. Lwin, S.; Li, Y.; Frenkel, A. I.; Wachs, I. E., Nature of $\mathrm{WO}_{x}$ Sites on $\mathrm{SiO}_{2}$ and Their Molecular Structure-Reactivity/Selectivity Relationships for Propylene Metathesis. ACS Catal. 2016, 6, 3061-3071. 
24. Mougel, V.; Chan, K.-W.; Siddiqi, G.; Kawakita, K.; Nagae, H.; Tsurugi, H.; Mashima, K.; Safonova, O.; Copéret, C., Low Temperature Activation of Supported Metathesis Catalysts by Organosilicon Reducing Agents. ACS Cent. Sci. 2016, 2, 569-576.

25. Yamamoto, K.; Chan, K. W.; Mougel, V.; Nagae, H.; Tsurugi, H.; Safonova, O. V.; Mashima, K.; Coperet, C., Silica-supported isolated molybdenum di-oxo species: formation and activation with organosilicon agent for olefin metathesis. Chem. Commun. 2018, 54, 3989-3992.

26. Chan, K. W.; Lam, E.; D’Anna, V.; Allouche, F.; Michel, C.; Safonova, O. V.; Sautet, P.; Copéret, C., C-H Activation and Proton Transfer Initiate Alkene Metathesis Activity of the Tungsten(IV)-Oxo Complex. J. Am. Chem. Soc. 2018, 140, 11395-11401.

27. Schrock, R. R.; DePue, R. T.; Feldman, J.; Yap, K. B.; Yang, D. C.; Davis, W. M.; Park, L.; DiMare, M.; Schofield, M., Further studies of imido alkylidene complexes of tungsten, well-characterized olefin metathesis catalysts with controllable activity. Organometallics 1990, 9, 22622275 .

28. Tsang, W. C. P.; Hultzsch, K. C.; Alexander, J. B.; Bonitatebus, P. J.; Schrock, R. R.; Hoveyda, A. H., Alkylidene and Metalacyclic Complexes of Tungsten that Contain a Chiral Biphenoxide Ligand. Synthesis, Asymmetric Ring-Closing Metathesis, and Mechanistic Investigations. J. Am. Chem. Soc. 2003, 125, 2652-2666.

29. Lopez, L. P. H.; Schrock, R. R., Formation of Dimers That Contain Unbridged W(IV)/W(IV) Double Bonds. J. Am. Chem. Soc. 2oo4, 126, 9526-9527.

30. Lopez, L. P. H.; Schrock, R. R.; Müller, P., Dimers that Contain Unbridged W(IV)/W(IV) Double Bonds. Organometallics 2oo6, 25, $1978-1986$.

31. Arndt, S.; Schrock, R. R.; Müller, P., Synthesis and Reactions of Tungsten Alkylidene Complexes That Contain the 2,6Dichlorophenylimido Ligand. Organometallics 2007, 26, 1279-1290.

32. Solans-Monfort, X.; Coperet, C.; Eisenstein, O., Shutting Down Secondary Reaction Pathways: The Essential Role of the Pyrrolyl Ligand in Improving Silica Supported d ${ }^{\mathrm{o}}-\mathrm{ML}_{4}$ Alkene Metathesis Catalysts from DFT Calculations. J. Am. Chem. Soc. 2010, 132, $7750-7757$.

33. Copéret, C.; Chabanas, M.; Petroff Saint-Arroman, R.; Basset, J.-M., Homogeneous and Heterogeneous Catalysis: Bridging the Gap through Surface Organometallic Chemistry. Angew. Chem. Int. Ed. 2003, 42, 156-181.

34. Copéret, C.; Comas-Vives, A.; Conley, M. P.; Estes, D. P.; Fedorov, A.; Mougel, V.; Nagae, H.; Núñez-Zarur, F.; Zhizhko, P. A., Surface Organometallic and Coordination Chemistry toward Single-Site Heterogeneous Catalysts: Strategies, Methods, Structures, and Activities. Chem. Rev. 2016, $116,323-421$.

35. Copéret, C., Single-Sites and Nanoparticles at Tailored Interfaces Prepared via Surface Organometallic Chemistry from Thermolytic Molecular Precursors. Acc. Chem. Res. 2019.

36. Amakawa, K.; Sun, L.; Guo, C.; Hävecker, M.; Kube, P.; Wachs, I. E.; Lwin, S.; Frenkel, A. I.; Patlolla, A.; Hermann, K.; Schlögl, R.; Trunschke, A., How Strain Affects the Reactivity of Surface Metal Oxide Catalysts. Angew. Chem. Int. Ed. 2013, 52, $13553-13557$.

37. Delley, M. F.; Praveen, C. S.; Borosy, A. P.; Núñez-Zarur, F.; Comas-Vives, A.; Copéret, C., Olefin polymerization on Cr(III)/SiO ${ }_{2}$ : Mechanistic insights from the differences in reactivity between ethene and propene. J. Catal. 2017, 354, 223-230.

38. Delley, M. F.; Núñez-Zarur, F.; Conley, M. P.; Comas-Vives, A.; Siddiqi, G.; Norsic, S.; Monteil, V.; Safonova, O. V.; Copéret, C., Proton transfers are key elementary steps in ethylene polymerization on isolated chromium(III) silicates. Proc. Natl. Acad. Sci. 2014, 111, 11624.

39. Estes, D. P.; Siddiqi, G.; Allouche, F.; Kovtunov, K. V.; Safonova, O. V.; Trigub, A. L.; Koptyug, I. V.; Copéret, C., C-H Activation on Co,O Sites: Isolated Surface Sites versus Molecular Analogs. J. Am. Chem. Soc. 2016, 138, 14987-14997.

40. Coperet, C., C-H Bond Activation and Organometallic Intermediates on Isolated Metal Centers on Oxide Surfaces. Chem. Rev. 2o1o, $110,656-680$.

41. $\quad$ Blanc, F.; Copéret, C.; Thivolle-Cazat, J.; Basset, J.-M.; Lesage, A.; Emsley, L.; Sinha, A.; Schrock, R. R., Surface versus Molecular Siloxy Ligands in Well-Defined Olefin Metathesis Catalysts: $\left[\left\{(\mathrm{RO})_{3} \mathrm{SiO}\right\} \mathrm{Mo}(=\mathrm{NAr})(=\mathrm{CH} t \mathrm{Bu})\left(\mathrm{CH}_{2} t \mathrm{Bu}\right)\right]$. Angew. Chem. Int. Ed. 20o6, 45, 1216-1220.

42. Laverty, D. T.; Rooney, J. J.; Stewart, A., Possible role of hydrido-metal complexes in metathesis, isomerization, dimerization, and polymerization of alkenes. J. Catal. 1976, 45, 110-113.

43. Amakawa, K.; Wrabetz, S.; Kröhnert, J.; Tzolova-Müller, G.; Schlögl, R.; Trunschke, A., In Situ Generation of Active Sites in Olefin Metathesis. J. Am. Chem. Soc. 2012, 134, 11462-11473.

44. Bluemel, J., Reactions of Ethoxysilanes with Silica: A Solid-State NMR Study. J. Am. Chem. Soc. 1995, 117, $2112-2113$.

45. Malfait, W. J.; Verel, R.; Koebel, M. M., Hydrophobization of Silica Aerogels: Insights from Quantitative Solid-State NMR Spectroscopy. J. Phys. Chem. C 2014, 118, 25545-25554.

46. Gunther, W. R.; Michaelis, V. K.; Griffin, R. G.; Román-Leshkov, Y., Interrogating the Lewis Acidity of Metal Sites in Beta Zeolites with ${ }^{15} \mathrm{~N}$ Pyridine Adsorption Coupled with MAS NMR Spectroscopy. J. Phys. Chem. C 2016, 120, 28533-28544.

47. Moroz, I. B.; Larmier, K.; Liao, W.-C.; Copéret, C., Discerning $\gamma$-Alumina Surface Sites with Nitrogen-15 Dynamic Nuclear Polarization Surface Enhanced NMR Spectroscopy of Adsorbed Pyridine. J. Phys. Chem. C 2018, 122, 10871-10882.

48. $\quad{ }^{15} \mathrm{~N}$ chemical shift of py-B $\left(\mathrm{C}_{6} \mathrm{~F}_{5}\right)_{3}$ adduct in $\mathrm{C}_{6} \mathrm{D}_{6}$ solution is at $\delta 233 \mathrm{ppm}$ (see Figure S21), which is lower than that of ${ }^{15} \mathrm{~N}-\mathrm{F} 6$.

49. Parry, E. P., An infrared study of pyridine adsorbed on acidic solids. Characterization of surface acidity. J. Catal. 1963, 2, 371-379.

50. Busca, G., Spectroscopic characterization of the acid properties of metal oxide catalysts. Catal. Today 1998, 41, 191-206.

51. Zaki, M. I.; Hasan, M. A.; Al-Sagheer, F. A.; Pasupulety, L., In situ FTIR spectra of pyridine adsorbed on $\mathrm{SiO}_{2}-\mathrm{Al}_{2} \mathrm{O}_{3}, \mathrm{TiO}_{2}, \mathrm{ZrO}_{2}$ and $\mathrm{CeO}_{2}$ : general considerations for the identification of acid sites on surfaces of finely divided metal oxides. Colloids Surf. A Pysicochem. Eng. Asp. 2001, 190, 261-274.

52. Mayo, F. R., The dimerization of styrene. J. Am. Chem. Soc. 1968, 9o, 1289-1295.

53. Kuroki, T.; Ogawa, T.; Sekiguchi, Y.; Ikemura, T., Vapor-phase dimerization of styrene in the presence of silica-alumina catalyst. Ind. Eng. Chem. Prod. Res. Dev. 1983, 22, 234-237. 
Table of Contents

Rates of Olefin Metathesis

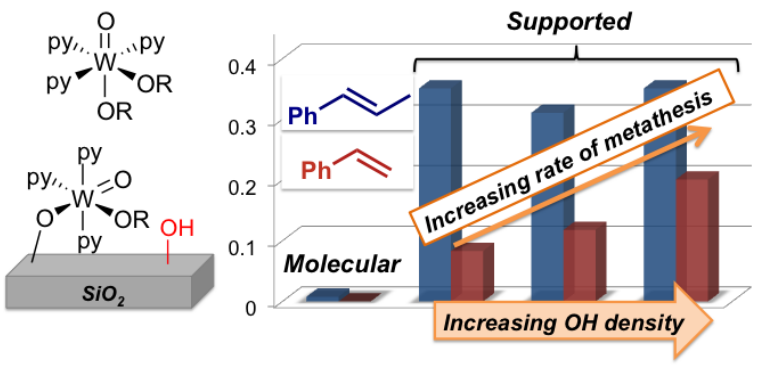

